\title{
Economic evaluation of anti-TNF agents for patients with rheumatoid arthritis in Greece
}

This article was published in the following Dove Press journal:

ClinicoEconomics and Outcomes Research

16 January 2015

Number of times this article has been viewed

\section{Vasilis Fragoulakis' \\ Elli Vitsou ${ }^{2}$ \\ Ana Cristina Hernandez ${ }^{2}$ \\ Nikolaos Maniadakis'}

'National School of Public Health, 2Pfizer Hellas, Athens, Greece
Correspondence: $\vee$ Fragoulakis Department of Health Services Management, National School of Public Health, 196 Alexandras Avenue, Athens II52I, Greece

Tel +302106467097

$\mathrm{Fax}+302132010194$

Email vfragoulakis@esdy.edu.gr
Objectives: We aimed to estimate the total mean annual treatment cost of different therapy options for patients with moderate-to-severe rheumatoid arthritis (RA) in Greece.

Methods: A cost-minimization approach was adopted. An economic model was developed to estimate the direct costs of the three widely used treatments within a 1-year time horizon, from a health care payer perspective, either for new or for existing patients. Data on resource use, dose escalation, and frequency of therapy were based on a nationwide field survey of rheumatologists. Other analyses were also undertaken based on evidence from the literature. Total cost comprised the cost of drugs, administration, and hospital day care visits. Unit cost data were obtained from the price bulletin and the government gazettes issued by the Ministry of Health. Due to the short time horizon of the study, the cost was not discounted.

Results: The mean annual total cost per new (or per existing) responder patient on etanercept was estimated at $€ 9,845(€ 9,840)$, and the total cost on etanercept/methotrexate (MTX) was estimated at $€ 9,857$ ( $€ 9,852)$. Therapy with etanercept had lower annual cost relative to adalimumab and infliximab. On an annual basis, it was estimated that the difference between etanercept monotherapy and adalimumab monotherapy was $€ 544(€ 1,323)$. Similarly, the difference between etanercept/MTX and infliximab/MTX was $€ 1,871(€ 1,490)$ and $€ 543(€ 1,323)$, respectively, relative to adalimumab/MTX. Results remained constant under other scenario analyses undertaken.

Conclusion: In the real-life practice setting in Greece, where dose intensity and frequency differences occur, etanercept alone or in combination with MTX, if prescribed as per label, represents the option with lower annual cost per patient when compared with adalimumab or infliximab in patients with RA. These results hold true as long as the assumptions and data used in the analysis remain stable and may alter if any of the underlying parameters, such as drug price, change.

Keywords: etanercept, dose escalation, economic analysis

\section{Introduction}

Rheumatoid arthritis (RA) is an inflammatory disease characterized by persistent synovitis, systemic inflammation, and autoantibodies. ${ }^{1}$ Several studies have reported overall RA prevalence rates of up to $0.67 \%$ of the total population, and they have also indicated that it is more common amongst women rather than men. ${ }^{2-6}$ Several cost-of-illness studies undertaken in a variety of settings and countries, including the USA, ${ }^{7-12}$ Canada, ${ }^{13}$ the Netherlands, ${ }^{14}$ Sweden, ${ }^{15}$ and Germany, ${ }^{16}$ have indicated that RA imposes a significant direct and indirect burden on patients, their families, and society overall. This has been also confirmed by a recent review of the literature that considered 127 relevant articles. ${ }^{17}$ Boonen and Severens combined results coming 
from 26 cost-of-illnesses studies and estimated that the total mean annual cost per RA patient was about $€ 21,900$, which is a noticeable figure. ${ }^{18}$

The European League Against Rheumatism (EULAR) and the American College of Rheumatology (ACR) have developed treatment guidelines for RA patients. ${ }^{19,20}$ These recommend the use of biological disease modifying antirheumatic drugs (DMARDS) after the failure of conventional DMARDS or as a first-line therapy option for patients with poor prognostic factors. ${ }^{19,20}$ Similar recommendations have been elaborated for the case of Greece. ${ }^{21,22}$ Existing evidence suggests that timely introduction of biologic DMARDS may improve clinical outcomes, induce remission, prevent radiographic progression, improve quality of life, and reduce lost work days or early retirement. ${ }^{23}$ The HOPE study reported that reduced or delayed access to appropriate RA treatment can cause considerable economic burden to patients and society, due to the significant costs associated with the higher consumption of health services needed for treating advanced-stage disease, higher productivity losses, and disability benefits. ${ }^{24}$

In addition to timely access to therapy, treatment costs are dependent on the intensity and frequency of drug doses prescribed in real-life settings. Furthermore, the mode of administration of the therapeutic options differs and hence, their resource utilization. Therefore, from a payer's perspective, the actual cost of therapy depends on the type of medication prescribed and its unit price on the one hand, and on the other hand, the frequency and dose prescribed in real-life settings. For these reasons, several analyses reported in the literature have attempted to compare the alternative therapies in terms of their costs, based on data from clinical practice, and in fact, they have indicated profound differences amongst the alternative therapies. ${ }^{25-37}$ Given the aforementioned, to make rational comparisons and subsequent choices between alternative therapies for RA on the basis of economic evidence, the actual prescribed doses in real-life settings must be considered and therapies should be evaluated based on their actual, rather than theoretical cost.

Greece is going through a very deep and sustained economic crisis, which has eliminated a significant portion of its gross domestic product (GDP) and which has had profound social, financial, political, health care, and health implications. ${ }^{38}$ An unprecedented reform is currently being implemented in the health care sector in order to increase efficiency in the funding and provision of services. The health care reforms in the domain of pharmaceuticals are attempting to revise the pricing and reimbursement system, to introduce prescription utilization and dispensing controls, and to restrain overall pharmaceutical expenditure through fixed budgets, price-volume, risk-sharing agreements, and similar measures. RA therapies represent one of the leading classes of products in terms of cost. Within this setting, and taking into account the aforementioned timing and cost determinants of RA therapy, it is paramount for payers to ensure that RA patients receive optimum therapy in terms of effectiveness but also, in terms of efficiency and cost-effectiveness. Given the number of patients and the size of budget concerned, the aforementioned should be a very important payer policy objective.

EOPYY, the National Organization for Health Services Provision, is the single national payer that was created from the merging of the health branches of all sickness funds in the country, and it provides coverage to all patients in the country. For the EOPYY, it is important to know the health and economic outcomes associated with the use of different biologic treatments for RA and hence, the rational for the present study, which was designed to provide some insights into this area.

\section{Methods}

Etanercept, infliximab, and adalimumab, represent three widely used anti-TNF (Tumor Necrosis Factor), available for the management of RA patients. ${ }^{39}$ The aim of the present study was to estimate the annual mean cost of treating an RA patient with etanercept, infliximab, and adalimumab either as monotherapy, when appropriate, or in combination with methotrexate (MTX), in the Greek health care setting. Although there is no direct comparative evidence on the relative efficacy of the three agents, an indirect comparison of randomized placebo-controlled trials undertaken in the context of a systematic review and meta-analysis of the literature indicated that there may be no substantial differences amongst them in terms of efficacy and safety. ${ }^{40}$ Hence the therapies were considered equivalent in terms of health outcomes, and therefore a cost-minimization analysis was undertaken on this grounds. This is the appropriate economic evaluation method in such cases. In this context, only the therapy cost associated with the use of each of the selected alternative treatments for RA in Greece was quantified. A Microsoft Excel ${ }^{\circledR}$ economic $^{2}$ model was developed to estimate the cost associated with actual prescribed drug and administration for each alternative therapy. The time horizon of the model was limited to 1 year. The cost of adverse events associated with the different comparators was not considered, as no significant differences amongst comparators were found. ${ }^{40}$ 
The model simulated patients during the course of a year and quantified the cost of resource consumption. In each therapy option, the model simulated results for two different groups of patients starting therapy, "responders" and "nonresponders". Responders were identified as those who attained the minimum improvement criterion for RA, ACR 20, defined by the ACR as a $20 \%$ improvement in the counts of the number of tender and swollen joints and at least three items from the following: observer evaluation of overall disease activity; patient evaluation of overall disease activity; patient evaluation of pain; a score of physical disability; and improvements in blood acute phase responses.

The model assumed that treated patients who had attained an ACR 20, continued to maintain this improvement while on therapy with a specific biologic agent. The model assumed that nonresponders were evaluated and dropped out from therapy due to lack of efficacy after a period of 12 weeks. ${ }^{19}$ Results were estimated for patients starting therapy for the first time and for existing patients who continued on therapy for another year. The prices of the drugs used in the model were based on the price bulletin issued by the Ministry of Health. ${ }^{41}$ The cost of drug therapy was calculated based on the available package size and cost and the required dose per patient. The present analysis, as mentioned above, was conducted from a payer's perspective. This analysis includes the cost of pharmaceuticals, expressed in hospital price, and the cost of administration related to day care hospitalization (ie, infusion for intravenous therapies) or physician visit (ie, for outpatient subcutaneous therapies).

The main input parameters driving the results of the model were the dose and frequency of prescribed drugs. The MTX dose was assumed at $15 \mathrm{mg}$ per os per week. ${ }^{42}$ Anti-TNF recommended doses are: etanercept $50 \mathrm{mg}$, administered through a subcutaneous injection once a week, or $25 \mathrm{mg}$, administered by subcutaneous injections twice per week; infliximab $3 \mathrm{mg} / \mathrm{kg}$ at week 0,2 , and 6 , and every 8 weeks thereafter, administered by intravenous injection; and adalimumab $40 \mathrm{mg}$ every other week, administered by subcutaneous injection. ${ }^{43-45} \mathrm{~A}$ possibility for dose escalation and/or intensification is possible in the case of infliximab and adalimumab, as referenced in their respective Summary of Product Characteristics (SPC). ${ }^{44,45}$ Hence, after initial therapy, a possibility for dose and frequency increase was incorporated into the model, for the latter two therapy options.

Data concerning the dose escalation were obtained from a nationwide physician survey, performed during a 2-month period between July and August of 2013. The data were collected through 10-minute telephone interviews with rheumatologists. Each participating physician was interviewed based on a structured questionnaire designed to collect information regarding the demographics of managed patients and the followed treatment patterns. Simple random sampling was used to select the interviewees. Specifically, participants were randomly selected through a publicly available database, which includes contact details for all registered members of the Hellenic Society of Rheumatology (http:// www.ere.gr). Sample size calculations were done prior to the study to make sure that the interviewed participants would constitute a representative sample of the rheumatologist population in Greece. A screening question was used to identify physicians who had used biologic agents for the treatment of RA in the last 12 months prior to interview. A weight was attached to each responder, based on the patient group size. These weights were then used to aggregate the responses of the interviewed sample.

The unit cost per item used in the model is shown in Table 1. Due to time horizon of the analysis, discounting was unnecessary. In studies such as the present one, there are a few uncertainties present either because of the nature of the assumptions necessary to undertake the analysis or because of the uncertainly and variability of the data utilized. Based on the data collected, an empirical distribution was estimated, and it was then used to run a probabilistic sensitivity analysis. Specifically, the dose and frequency of escalation variables were associated with the empirical distributions; then, in each of 10,000 simulations, a different variable was drawn at random from the distribution, and the results were recalculated. The set of obtained results was then used to estimate uncertainty intervals. Moreover, to further test the robustness of the results, alternative scenarios were tested, where data on dose escalation were based on evidence derived from the literature. In this context, the economic analysis was undertaken two more times. In the first scenario, the escalation rate was: $2.5 \%$ for etanercept, $9.6 \%$ for adalimumab, and $35 \%$ for infliximab according to evidence from the DART study, ${ }^{32}$ and in the second scenario, the escalation rate was

Table I Unit cost per item used in the model

\begin{tabular}{ll}
\hline Description & Cost $(\boldsymbol{\epsilon})$ \\
\hline Etanercept $50 \mathrm{mg} / \mathrm{I} \mathrm{mL} \times 4$ prefilled syringe & 756.96 \\
Infliximab $100 \mathrm{mg} /$ vial $^{\prime}$ & 426.00 \\
Adalimumab $40 \mathrm{mg}$ & 381.39 \\
Methotrexate $2.5 \mathrm{mg} /$ tablet, 100 tablet bottle & 3.57 \\
Physician office visit & 5.00 \\
Day care hospitalization $^{\mathrm{b}}$ & 85.00 \\
\hline
\end{tabular}

Notes: ${ }^{2}$ Ministerial Decision, Y4a/oik105604/27/09/20II; 'Government Gazette FEK2080/B2010. 
$0 \%, 0 \%$, and $55 \%$ respectively, according to evidence from the Hellenic Registry of Biologics. ${ }^{46}$

\section{Results}

The sample of participating physicians in the survey consisted of 96 rheumatologists who were based in Athens (69\%), Thessaloniki (13\%), and other urban areas (18\%), such as Patras, Larissa, and Heraklion. Assuming from the published literature a prevalence of disease of $0.67 \% \%^{5}$, the moderate/severe RA patient population in Greece may be estimated at around 27,000 cases. Altogether, the physicians included in the study reported treating 4,015 patients in the year of the study, and thus it may be inferred that they were treating about $15 \%$ of all moderate/severe patients in Greece, which is a significant sample size. About one-third (33\%) of the patients managed by those participating physicians were male and the remaining (67\%) were female.

For patient cases on infliximab who experienced lack of response, either the dose was increased from $3 \mathrm{mg} / \mathrm{kg}$ to $4.5 \mathrm{mg} / \mathrm{kg}$ or the interval reduced from 8 to 6 weeks, and these figures were used in the baseline analysis. ${ }^{47}$ For patient cases on adalimumab who experience lack of response, the dose increase was from $40 \mathrm{mg}$ to $73.9 \mathrm{mg}$ and the dose interval was reduced from every other week to every week, and this is assumed in the analysis. ${ }^{26}$ Moreover, as seen in Table 2, the initial prescribed dose of infliximab in about one-third of patients was not the one recommended in the SPC but rather, was higher in dose intensity $(14.3 \%)$ or frequency $(11.9 \%)$, or in a combination of the two (3.6\%). As seen in Figure 1, the results of the study indicated that the dose of adalimumab-based therapy was increased in $9.4 \%$ of patients, while the frequency of dose was increased in $4.0 \%$ of them. For patients receiving infliximab-based therapy, the dose increased in $10.0 \%$ of the cases and the frequency in $11.3 \%$ of them.

The base case economic analysis is presented in Table 3 , whilst Figures 2 and 3 present probabilistic results. The mean annual total cost per new (or per existing) responder patient on etanercept was estimated at $€ 9,845(€ 9,840)$, and the total

Table 2 The initial dosage scheme of infliximab

\begin{tabular}{ll}
\hline Dosage scheme & $\%$ of patients \\
\hline $3 \mathrm{mg} / \mathrm{kg}$ every 8 weeks (as per label) & $70.20 \%$ \\
$5 \mathrm{mg} / \mathrm{kg}$ every 8 weeks & $14.30 \%$ \\
$3 \mathrm{mg} / \mathrm{kg}$ every 6 weeks & $11.90 \%$ \\
$5 \mathrm{mg} / \mathrm{kg}$ every 6 weeks & $3.60 \%$ \\
Total & $100.00 \%$ \\
\hline
\end{tabular}

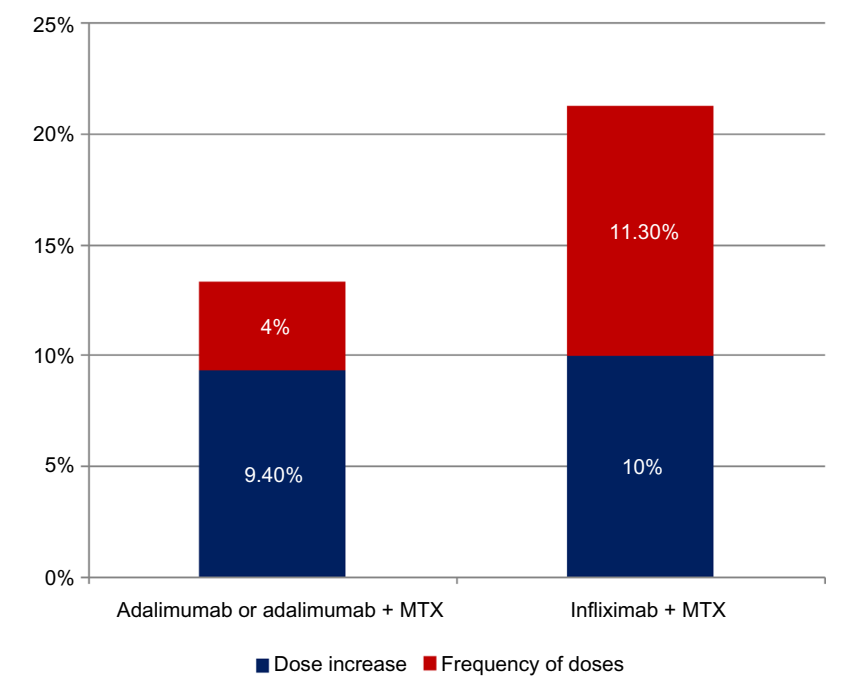

Figure I Percent of cases of dose escalation and frequency intensification. Abbreviation: MTX, methotrexate.

cost on etanercept/MTX was estimated at $€ 9,857$ (€9,852). Therapy with etanercept had lower annual cost relative to its comparators. In particular, on an annual basis, it was estimated that the difference between etanercept monotherapy and adalimumab monotherapy was $€ 544$ (€1,323). Similarly, the difference between etanercept/MTX and infliximab/MTX was $€ 1,871(€ 1,490)$ and $€ 543(€ 1,323)$, respectively, relative to adalimumab/MTX.

It must be highlighted that, in accordance with the base case scenario, the results imply that for every 1,000 new patients prescribed with etanercept/MTX relative to infliximab/MTX, there are $€ 1.871$ million annual savings, and relative to adalimumab/MTX, there are $€ 0.543$ million savings. Also, for every 1,000 patients prescribed with etanercept monotherapy, there are $€ 0.544$ million annual savings relative to adalimumab monotherapy.

The results of the probabilistic analysis are reflected in the uncertainty confidence intervals in the aforementioned table. In accordance with the probabilistic results, etanercept represents the option with the lowest cost compared with comparators, indicating a statistically significant difference based on $95 \%$ level of significance. The two scenario analyses are presented in Table 4 . In the first scenario analysis, the cost of an existing patient responding to therapy with etanercept was estimated at $€ 10,086$, followed by etanercept/MTX (€10,098), infliximab/MTX (€9,133), adalimumab (€10,868), and adalimumab/MTX (€10,880). In the second scenario, the cost for etanercept, etanercept/ MTX, infliximab/MTX, adalimumab, and adalimumab/ MTX were estimated to be $€ 9,840, € 9,852, € 10,397, € 9,916$, and $€ 9,927$, respectively. 
Table 3 Average cost per patient per year for the base case scenario (in €)

\begin{tabular}{|c|c|c|c|}
\hline & \multicolumn{2}{|l|}{ New patients } & \multirow{2}{*}{$\begin{array}{l}\text { Existing patients** } \\
\text { Responders }\end{array}$} \\
\hline & Nonresponders & Responders* & \\
\hline Etanercept & 2,276 (NA) & 9,845 (NA) & 9,840 (NA) \\
\hline Etanercept + MTX & 2,278 (NA) & 9,857 (NA) & 9,852 (NA) \\
\hline Infliximab + MTX & $3,17 \mid(N A)$ & II,728 (II,642-II,8I3) & $I I, 342(|0,47|-|2,2| I)$ \\
\hline Adalimumab & $2,293(\mathrm{NA})$ & $10,389(10,289-10,485)$ & II,I63 (I0,9|5-II,404) \\
\hline Adalimumab + MTX & 2,296 (NA) & $10,400(10,300-10,497)$ & $11,175(10,927-11,417)$ \\
\hline
\end{tabular}

Notes: Values are expressed as mean $(95 \% \mathrm{UI})$, where UI was the lower and upper uncertainty interval from I0,000 Monte Carlo simulations. *Minimum improvement criteria for a responder were the "ACR 20 " (the definition requires, among other prerequisites, a $20 \%$ improvement in both tender and swollen joint counts); ${ }^{58 *}$ previously treated patients who were continuing therapy and who achieved an improvement greater than the minimum criteria of ACR 20.

Abbreviations: ACR, American College of Rheumatologists; MTX, methotrexate; NA, not available; UI, uncertainty interval.

\section{Discussion}

Understanding the relative outcomes of alternative therapy strategies for patients with RA is important in order to ensure that patients not only receive effective but also, efficient or otherwise cost-effective care. The aim of the present study was to assess the economic impact of use of biologic agents for RA treatment on the local payer budget. Considering that no substantial efficacy and safety differences among agents exist, ${ }^{40}$ a cost-minimization analysis was considered as the appropriate methodological approach to evaluate alternative therapies from an economic perspective. Adalimumab, etanercept, and infliximab represent the standards of practice in the management of RA patients in Greece. In this analysis, etanercept, alone or in combination with MTX, represents the least costly option and has lower financial impact in the Greek health care payer relative to adalimumab and infliximab. In particular, based on the present analysis conducted, etanercept represents the least costly option for existing and new patients responding to therapy as well as for those not responding to therapy, followed by adalimumab and then infliximab. In the present model, the observed differences in costs amongst these agents were a result of dose escalation and treatment intensification differences in real-life practice as detected by a field-based survey.

The present analysis has several strengths. To the best of our knowledge, this is the first economic study conducted for anti-TNFs in RA patients in Greece. It is based on a large and representative sample of practicing physicians, which permits generalizations of the results to a nationwide basis. Moreover, data from a local registry ${ }^{46}$ were also considered in the analysis, to study alternative scenarios. The present findings are consistent with those from other economic analyses undertaken in other countries, which have showed that etanercept may have lower cost per treated

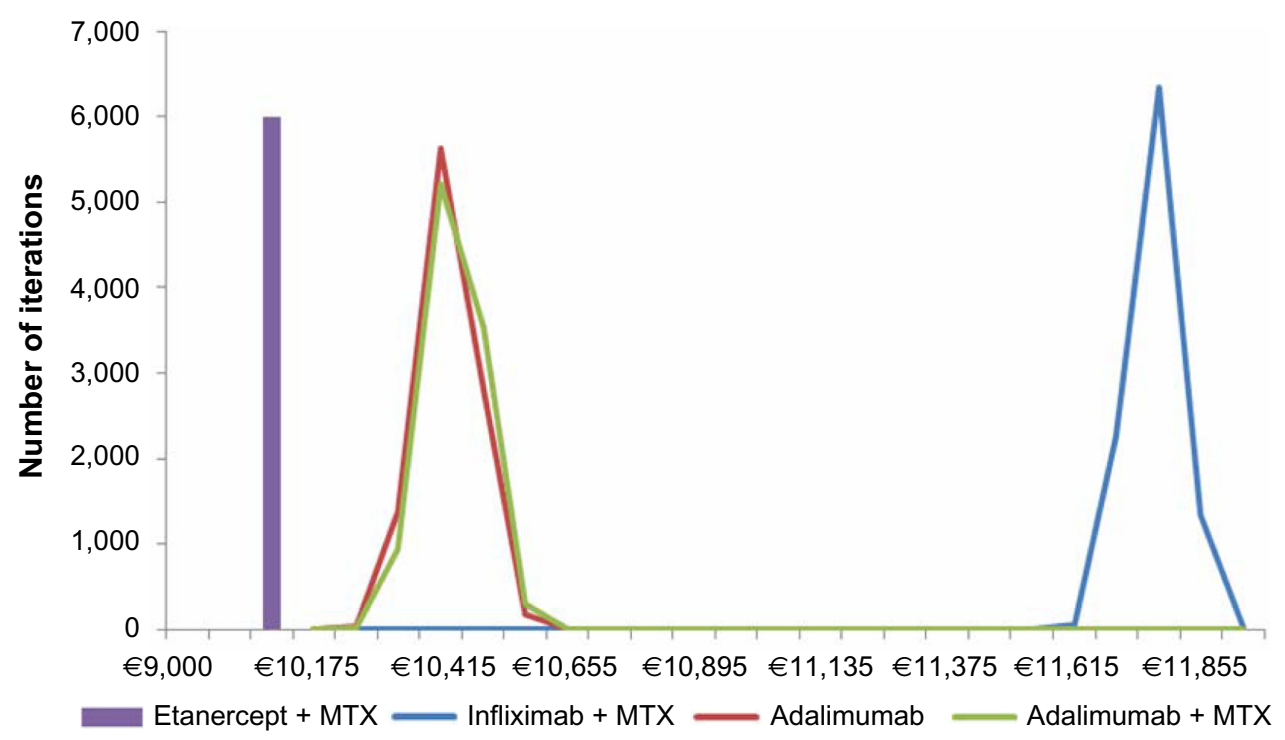

Figure 2 Mean total treatment cost per year for new patient. Note: Results were based on 10,000 Monte Carlo simulations. Abbreviation: MTX, methotrexate. 


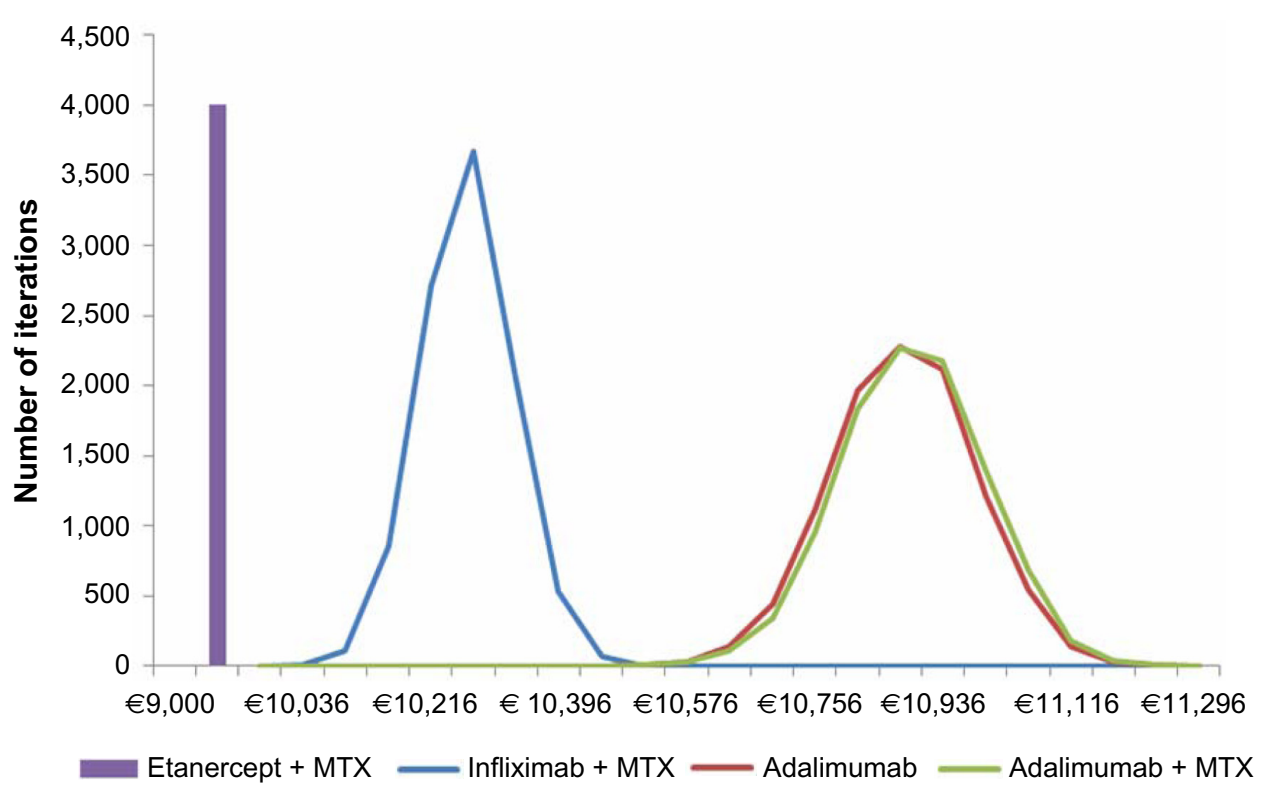

Figure 3 Mean total treatment cost per year for existing patient. Note: Results were based on 10,000 Monte Carlo simulations.

Abbreviation: MTX, methotrexate.

patient compared with adalimumab and infliximab. ${ }^{32,48}$ Because of the economic importance of the treatments for RA, a large number of economic evaluations have been conducted to assess their cost-effectiveness, and several reviews have been undertaken to summarize what is known in this field. ${ }^{31,49-54}$ Evidence of the cost-effectiveness of the different therapies has been contradictory in published studies, due to the heterogeneity of the approaches applied and the assumption needed regarding the relative effectiveness differences between therapy options. ${ }^{55}$ Hence, many commentators and national agencies argue for the case of cost-minimization analysis as a preferable approach to inform decision making regarding allocation of health care resources for RA patients. This is a more straightforward and less controversial approach and is a strong element of the present study. ${ }^{56}$ Moreover, the findings from the local survey concerning the dose escalation and frequency adaptation have been consistent with the findings reported in the related literature. For instance, a retrospective review of medical records from five European countries (DART study) also showed that $9.6 \%$ of adalimumab patients and $35 \%$ of infliximab patients required dose escalation in the

Table 4 Average cost per patient per year for two scenario analysis (in $€$ )

\begin{tabular}{|c|c|c|c|}
\hline & \multicolumn{2}{|l|}{ New patients } & \multirow{2}{*}{$\frac{\text { Existing patients** }}{\text { Responders }}$} \\
\hline & Nonresponders & Responders* & \\
\hline \multicolumn{4}{|c|}{ Scenario I Dose escalation: 2.5\% (etanercept), 9.6\% (adalimumab), and 35\% (infliximab) (DART study } \\
\hline Etanercept & $2,276(\mathrm{NA})$ & $9,938(9,932-9,944)$ & $10,086(10,070-10,103)$ \\
\hline Etanercept + MTX & $2,278(\mathrm{NA})$ & $9,949(9,943-9,955)$ & $10,098(10,082-10,114)$ \\
\hline Infliximab + MTX & $3,17 \mid(N A)$ & $10,581(10,496-10,666)$ & $9,133(8,967-9,298)$ \\
\hline Adalimumab & $2,293(\mathrm{NA})$ & $10,278(10,255-10,302)$ & $10,868(10,807-10,929)$ \\
\hline Adalimumab + MTX & $2,296(\mathrm{NA})$ & $10,290(10,267-10,313)$ & $10,880(10,819-10,942)$ \\
\hline \multicolumn{4}{|c|}{ Scenario 2 Dose escalation: 0\% (etanercept), $0 \%$ (adalimumab), and $55 \%$ (infliximab) (Hellenic Registry ${ }^{46}$ ) } \\
\hline Etanercept & $2,276(\mathrm{NA})$ & $9,845(\mathrm{NA})$ & 9,840 (NA) \\
\hline Etanercept + MTX & $2,278(\mathrm{NA})$ & 9,857 (NA) & $9,852(\mathrm{NA})$ \\
\hline Infliximab + MTX & $3,|7|(N A)$ & $11,238(11,124-11,349)$ & $10,397(10,147-10,645)$ \\
\hline Adalimumab & $2,293(\mathrm{NA})$ & $9,921(\mathrm{NA})$ & $9,916(\mathrm{NA})$ \\
\hline Adalimumab + MTX & $2,296(\mathrm{NA})$ & $9,932(\mathrm{NA})$ & 9,927 (NA) \\
\hline
\end{tabular}

Notes: Values are expressed as mean $(95 \% \mathrm{UI})$, where $\mathrm{UI}$ was the lower and upper uncertainty interval from 10,000 Monte Carlo simulations. *Minimum improvement criteria for a responder were the "ACR 20" (the definition requires, among other prerequisites, a $20 \%$ improvement in both tender and swollen joint counts); 58 **previously treated patients who were continuing therapy and who achieved an improvement greater than the minimum criteria of ACR 20.

Abbreviations: ACR, American College of Rheumatologists; MTX, methotrexate; NA, not available; UI, uncertainty interval. 
course of biologic treatment. ${ }^{32}$ In addition, another study estimated that $12.5 \%$ of adalimumab patients and $42.5 \%$ of infliximab patients also underwent dose intensification. ${ }^{28}$ Other studies using different methodological approaches showed similar results, consistent with the present findings, which are somewhat lower and hence represent a conservative approach to the issue in hand. ${ }^{26,30,33}$ Notably, most of the previous analyses concluded that the dose escalation of adalimumab and infliximab were higher than those in the present study, resulting in higher relative cost differentials.

Despite the aforementioned strengths, it is acknowledged that common limitations and drawbacks still exist as the analysis was based on many assumptions and data coming from different sources. In particular, the data obtained from interviews might have been subject to participant recall bias. However, field-based research was considered as a reasonable approach for the purposes of this economic evaluation, in the absence of real-life data at the time of design of this study. In addition, the economic results of this model reflect mainly the specific setting, patient management practice, and drug prices. If these change, so may be the case for the conclusions. Also, the results have to be viewed in the context of the underlying model assumptions. Finally, indirect costs and costs to other parties were not taken into consideration.

A broader analysis from a societal perspective and with case-specific rather than physician data could be the scope of a future economic analysis.

\section{Conclusion}

It has been reported that in Greece, RA patients may face access barriers to appropriate biologic therapy. Thus, it is deemed necessary for the health care system to ensure that unrestricted and fairly easy access to all patients is guaranteed, especially in the context of restricted available budgets. In addition, under the pressure of the economic and financial turmoil, there is a growing recognition that comprehensive economic assessments are required, in order to study the economic implications of alternative treatment options and, therefore, to make more informed and better decisions and choices, and to maximize efficiency. ${ }^{57}$ The present paper revealed that in the real-life practice setting in Greece, where dose and frequency differences occur, etanercept alone or in combination with MTX, if prescribed as per SPC, represents the option with the lowest annual cost per patient when compared with adalimumab or infliximab in patients with RA. This represents a significant parameter that could be considered in clinical decisions concerning the use of biologic treatments in a cost-constrained environment.

Notwithstanding, the conditions upon which were estimated, these findings may be used by the payer to attain savings in its limited budget.

\section{Author contributions}

VF conducted analyses, interpreted the results and drafted the article. EV and $\mathrm{ACH}$ designed and supervised study, interpreted results and drafted the article. NM designed study, analyzed and interpreted data and supervised study.

All the authors revised and approved version to be published and are accountable for all aspects of work.

\section{Acknowledgments}

The authors would like to thank Vasilis Tsekouras and Katerina Bilitou from Pfizer Hellas for their in-depth review of the manuscript and Michalis Kalpaxoglou from IPSOS SA for carrying out the market research and analyzing the sample.

\section{Disclosure}

For the present study, VF has received an unrestricted grant from Pfizer. EV and AH are full time employees at Pfizer Hellas. VF and NM have received honoraria for lectures and seminars from Pfizer. The authors report no other conflicts of interest.

This paper does not guarantee the appropriateness of any medical treatment and is not intended to be used for therapeutic purposes or as a substitute for a health professional's advice.

\section{References}

1. Scott DL, Wolfe F, Huizinga TW. Rheumatoid arthritis. Lancet. 2010;376(9746):1094-1108.

2. Woolf AD, Pfleger B. Burden of major musculoskeletal conditions. Bull World Health Organ. 2003;81(9):646-656.

3. Wong R, Davis AM, Badley E, Grewal R, Mohammed M. Prevalence of Arthritis and Rheumatic Diseases Around the World. A Growing Burden and Implications for Health Care Needs. Toronto: Arthritis Community Research and Evaluation (ACREU); 2010. Available from: http://www. modelsofcare.ca/pdf/10-02.pdf. Accessed November 22, 2014.

4. Andrianakos A, Trontzas P, Christoyannis F, et al; ESORDIG Study. Prevalence of rheumatic diseases in Greece: a cross-sectional population based epidemiological study. The ESORDIG Study. J Rheumatol. 2003;30(7):1589-1601.

5. Andrianakos A, Trontzas P, Christoyannis F, et al; ESORDIG Study Group. Prevalence and management of rheumatoid arthritis in the general population of Greece - the ESORDIG study. Rheumatology (Oxford). 2006;45(12):1549-1554.

6. Andrianakos AA, Miyakis S, Trontzas P, et al; ESORDIG study group. The burden of the rheumatic diseases in the general adult population of Greece: the ESORDIG study. Rheumatology (Oxford). 2005;44(7): 932-938. 
7. Meenan RF, Yelin EH, Henke CJ, Curtis DL, Epstein WV. The costs of rheumatoid arthritis. A patient-oriented study of chronic disease costs. Arthritis Rheum. 1978;21(7):827-833.

8. Lubeck DP, Spitz PW, Fries JF, Wolfe F, Mitchell DM, Roth SH. A multicenter study of annual health service utilization and costs in rheumatoid arthritis. Arthritis Rheum. 1986;29(4):488-493.

9. Wolfe F, Kleinheksel SM, Spitz PW, et al. A multicenter study of hospitalization in rheumatoid arthritis. Frequency, medical-surgical admissions, and charges. Arthritis Rheum. 1986;29(5):614-619.

10. Liang MH, Larson M, Thompson M, et al. Costs and outcomes in rheumatoid arthritis and osteoarthritis. Arthritis Rheum. 1984;27(5): 522-529.

11. Yelin E, Wanke LA. An assessment of the annual and long-term direct costs of rheumatoid arthritis: the impact of poor function and functional decline. Arthritis Rheum. 1999;42(6):1209-1218.

12. Gabriel SE, Crowson CS, Campion ME, O'Fallon WM. Direct medical costs unique to people with arthritis. J Rheumatol. 1997;24(4):719-725.

13. Clarke AE, Zowall $\mathrm{H}$, Levinton $\mathrm{C}$, et al. Direct and indirect medical costs incurred by Canadian patients with rheumatoid arthritis: a 12 year study. J Rheumatol. 1997;24(6):1051-1060.

14. van Jaarsveld CH, Jacobs JW, Schrijvers AJ, Heurkens AH, Haanen HC, Bijlsma JW. Direct cost of rheumatoid arthritis during the first six years: a cost-of-illness study. Br J Rheumatol. 1998;37(8):837-847.

15. Jonsson B, Rehnberg C, Borgquist L, Larsson SE. Locomotion status and costs in destructive rheumatoid arthritis. A comprehensive study of 82 patients from a population of 13,000. Acta Orthop Scand. 1992;63(2): 207-212.

16. Merkesdal S, Ruof J, Schöffski O, Bernitt K, Zeidler H, Mau W. Indirect medical costs in early rheumatoid arthritis: composition of and changes in indirect costs within the first three years of disease. Arthritis Rheum. 2001;44(3):528-534.

17. Furneri G, Mantovani LG, Belisari A, et al. Systematic literature review on economic implications and pharmacoeconomic issues of rheumatoid arthritis. Clin Exp Rheumatol. 2012;30(4 Suppl 73):S72-S84.

18. Boonen A, Severens JL. The burden of illness of rheumatoid arthritis. Clin Rheumatol. 2011;30 Suppl 1:S3-S8.

19. Singh JA, Furst DE, Bharat A, et al. 2012 update of the 2008 American College of Rheumatology recommendations for the use of disease-modifying antirheumatic drugs and biologic agents in the treatment of rheumatoid arthritis. Arthritis Care Res (Hoboken). 2012;64(5): 625-639.

20. Saag KG, Teng GG, Patkar NM, et al; American College of Rheumatology. American College of Rheumatology 2008 recommendations for the use of nonbiologic and biologic disease-modifying antirheumatic drugs in rheumatoid arthritis. Arthritis Rheum. 2008;59(6):762-784.

21. [National Organizations for Medicines. Protocols for Medicine and Medical activities: Rheumatoid Arthritis v1.0]. Accessed at http://www. eof.gr/c/document_library/get_file?p_1_id=34765\&folderId=34627\&n ame=DLFE-1514.pdf. on November 22, 2014. Greek.

22. [Hellenic Rheumatology Society. Therapeutic Prescription Protocols: 08-006A. Established Rheumatoid Arthritis"] Accessed at: http://www. ere.gr/_pdf/08_006_A.pdf. on November 22, 2014. Greek.

23. Breedveld $F$. The value of early intervention in RA - a window of opportunity. Clin Rheumatol. 2011;30 Suppl 1:S33-S39.

24. Souliotis K, Papageorgiou M, Politi A, Ioakeimidis D, Sidiropoulos P. Barriers to accessing biologic treatment for rheumatoid arthritis in Greece: the unseen impact of the fiscal crisis - the Health Outcomes Patient Environment (HOPE) study. Rheumatol Int. 2014;34(1):25-33.

25. Escudero-Vilaplana V, Ramírez-Herraiz E, Trovato-López N, et al. Influence on effectiveness of early treatment with anti-TNF therapy in rheumatoid arthritis. J Pharm Pharm Sci. 2012;15(3):355-360.

26. Blom M, Kievit W, Kuper HH, et al. Frequency and effectiveness of dose increase of adalimumab, etanercept, and infliximab in daily clinical practice. Arthritis Care Res (Hoboken). 2010;62(9):1335-1341.

27. Blume SW, Fox KM, Joseph G, Chuang CC, Thomas J, Gandra SR. Tumor necrosis factor-blocker dose escalation in rheumatoid arthritis patients in a pharmacy benefit management setting. Adv Ther. 2013;30(5):517-527.
28. Bonafede MM, Gandra SR, Fox KM, Wilson KL. Tumor necrosis factor blocker dose escalation among biologic naïve rheumatoid arthritis patients in commercial managed-care plans in the 2 years following therapy initiation. J Med Econ. 2012;15(4):635-643.

29. Fisher MD, Watson C, Fox KM, Chen YW, Gandra SR. Dosing patterns of three tumor necrosis factor blockers among patients with rheumatoid arthritis in a large United States managed care population. Curr Med Res Opin. 2013;29(5):561-568.

30. Harrison DJ, Huang X, Globe D. Dosing patterns and costs of tumor necrosis factor inhibitor use for rheumatoid arthritis. Am J Health Syst Pharm. 2010;67(15):1281-1287.

31. Malottki K, Barton P, Tsourapas A, et al. Adalimumab, etanercept, infliximab, rituximab and abatacept for the treatment of rheumatoid arthritis after the failure of a tumour necrosis factor inhibitor: a systematic review and economic evaluation. Health Technol Assess. 2011;15(14):1-278.

32. Moots RJ, Haraoui B, Matucci-Cerinic M, et al. Differences in biologic dose-escalation, non-biologic and steroid intensification among three anti-TNF agents: evidence from clinical practice. Clin Exp Rheumatol. 2011;29(1):26-34.

33. Ollendorf DA, Klingman D, Hazard E, Ray S. Differences in annual medication costs and rates of dosage increase between tumor necrosis factor-antagonist therapies for rheumatoid arthritis in a managed care population. Clin Ther. 2009;31(4):825-835.

34. Ariza-Ariza R, Navarro-Sarabia F, Hernández-Cruz B, RodríguezArboleya L, Navarro-Compán V, Toyos J. Dose escalation of the anti-TNF-alpha agents in patients with rheumatoid arthritis. A systematic review. Rheumatology (Oxford). 2007;46(3):529-532.

35. Schabert VF, Bruce B, Ferrufino CF, et al. Disability outcomes and dose escalation with etanercept, adalimumab, and infliximab in rheumatoid arthritis patients: a US-based retrospective comparative effectiveness study. Curr Med Res Opin. 2012;28(4):569-580.

36. Ramírez-Herráiz E, Escudero-Vilaplana V, Alañón-Plaza E, et al. Efficiency of adalimumab, etanercept and infliximab in rheumatoid arthritis patients: dosing patterns and effectiveness in daily clinical practice. Clin Exp Rheumatol. 2013;31(4):559-565.

37. Huang X, Gu NY, Fox KM, Harrison DJ, Globe D. Comparison of methods for measuring dose escalation of the subcutaneous TNF antagonists for rheumatoid arthritis patients treated in routine clinical practice. Curr Med Res Opin. 2010;26(7):1637-1645.

38. Kentikelenis A, Karanikolos M, Papanicolas I, Basu S, McKee M, Stuckler D. Health effects of financial crisis: omens of a Greek tragedy. Lancet. 2011;378(9801):1457-1458.

39. Kumar P, Banik S. Pharmacotherapy options in rheumatoid arthritis. Clin Med Insights Arthritis Musculoskelet Disord. 2013;6:35-43.

40. Gartlehner G, Hansen RA, Jonas BL, Thieda P, Lohr KN. The comparative efficacy and safety of biologics for the treatment of rheumatoid arthritis: a systematic review and metaanalysis. J Rheumatol. 2006;33(12):2398-2408.

41. Greek Ministry of Health. Drug Price Bulletin. Accessed at November 2014; Available at: www.yyka.gov.gr/. Accessed November 22, 2014. Greek.

42. Migliore A, Bizzi E, Massafra U, et al. Can Cyclosporine-A associated to methotrexate maintain remission induced by anti-TNF agents in rheumatoid arthritis patients? (Cynar pilot study). Int J Immunopathol Pharmacol. 2010;23(3):783-790.

43. European Medicines Agency. Annex I. Summary of Product Characteristics [Embrel $25 \mathrm{mg}$ powder and solvent for solution for injection]. London: European Medicines Agency; . Available from: http://www.ema.europa.eu/docs/en_GB/document_library/EPAR_-_ Product_Information/human/000262/WC500027361.pdf. Accessed November 22, 2014.

44. European Medicines Agency. Annex I. Summary of Product Characteristics [Remicade $100 \mathrm{mg}$ powder for concentrate for solution for infusion]. London: European Medicines Agency; Available from: http://www.ema. europa.eu/docs/en_GB/document_library/EPAR_-_Product_Information/human/000240/WC500050888.pdf. Accessed November 22, 2014. 
45. European Medicines Agency. Annex I. Summary of Product Characteristics [Humira $40 \mathrm{mg} / 0.8 \mathrm{ml}$ for injection for paediatric use]. London: European Medicines Agency; . Available from: http://www.ema.europa. eu/docs/en_GB/document_library/EPAR_-_Product_Information/ human/000481/WC500050870.pdf. Accessed November 22, 2014.

46. Flouri I, Markatseli TE, Voulgari PV, et al. Comparative effectiveness and survival of infliximab, adalimumab, and etanercept for rheumatoid arthritis patients in the Hellenic Registry of Biologics: Low rates of remission and 5-year drug survival. Semin Arthritis Rheum. 2014;43(4): 447-457.

47. Rahman MU, Strusberg I, Geusens P, et al. Double-blinded infliximab dose escalation in patients with rheumatoid arthritis. Ann Rheum Dis. 2007;66(9):1233-1238.

48. Bonafede M, Joseph GJ, Princic N, Harrison DJ. Annual acquisition and administration cost of biologic response modifiers per patient with rheumatoid arthritis, psoriasis, psoriatic arthritis, or ankylosing spondylitis. J Med Econ. 2013;16(9):1120-1128.

49. Liu Y, Wu EQ, Bensimon AG, et al. Cost per responder associated with biologic therapies for Crohn's disease, psoriasis, and rheumatoid arthritis. Adv Ther. 2012;29(7):620-634.

50. Tsao NW, Bansback NJ, Shojania K, Marra CA. The issue of comparators in economic evaluations of biologic response modifiers in rheumatoid arthritis. Best Pract Res Clin Rheumatol. 2012;26(5):659-676.

51. Bansback NJ, Regier DA, Ara R, et al. An overview of economic evaluations for drugs used in rheumatoid arthritis : focus on tumour necrosis factor-alpha antagonists. Drugs. 2005;65(4):473-496.
52. Chen YF, Jobanputra P, Barton P, et al. A systematic review of the effectiveness of adalimumab, etanercept and infliximab for the treatment of rheumatoid arthritis in adults and an economic evaluation of their cost-effectiveness. Health Technol Assess. 2006;10(42):iii-iv, xi.

53. Doan QV, Chiou CF, Dubois RW. Review of eight pharmacoeconomic studies of the value of biologic DMARDs (adalimumab, etanercept, and infliximab) in the management of rheumatoid arthritis. J Manag Care Pharm. 2006;12(7):555-569.

54. Sullivan SD, Alfonso-Cristancho R, Carlson J, Mallya U, Ringold S. Economic consequences of sequencing biologics in rheumatoid arthritis: a systematic review. J Med Econ. 2013;16(3):391-396.

55. Her M, Kavanaugh A. Critical analysis of economic tools and economic measurement applied to rheumatoid arthritis. Clin Exp Rheumatol. 2012;30(4 Suppl 73):S107-SS111.

56. Iannazzo S, De Francesco M, Gomez-Ulloa D, Benucci M. A review of cost-effectiveness evaluations as part of national health technology assessments of biologic DMARDs in the treatment of rheumatoid arthritis. Expert Rev Pharmacoecon Outcomes Res. 2013;13(4): $455-468$.

57. Sullivan SD, Mauskopf JA, Augustovski F, et al. Budget impact analysis-principles of good practice: report of the ISPOR 2012 Budget Impact Analysis Good Practice II Task Force. Value Health. 2014;17(1) 5-14.

58. Escalante A, Haas RW, del Rincón I. Measurement of global functional performance in patients with rheumatoid arthritis using rheumatology function tests. Arthritis Res Ther. 2004;6(4):R315-R325.
ClinicoEconomics and Outcomes Research

\section{Publish your work in this journal}

ClinicoEconomics \& Outcomes Research is an international, peerreviewed open-access journal focusing on Health Technology Assessment, Pharmacoeconomics and Outcomes Research in the areas of diagnosis, medical devices, and clinical, surgical and pharmacological intervention. The economic impact of health policy and health systems

\section{Dovepress}

organization also constitute important areas of coverage. The manuscript management system is completely online and includes a very quick and fair peer-review system, which is all easy to use. Visit http://www.dovepress.com/testimonials.php to read real quotes from published authors. 